\title{
Educação patrimonial no ensino formal: consciência e participação cidadã
}

\author{
Larizza Bergui de Andrade ${ }^{1}$ \\ ORCID: 0000-0001-7879-5614 \\ Nadja de Carvalho Lamas ${ }^{1}$ \\ ORCID: 0000-0003-1305-123X
}

\section{Resumo}

0 artigo decorre de uma pesquisa qualitativa sobre as pinturas murais do artista plástico Luiz Carlos da Silva, conhecido como Luiz Si, em 21 escolas municipais de Joinville, realizadas durante processo educacional previsto no projeto 0 Artista na Educação, idealizado e executado pelo próprio artista, entre os anos de 1996 a 2009. As pinturas, de grande porte, destacam-se em seu valor representativo por incluir às paisagens figuras que referenciam a cultura local. Seu valor representativo também diz respeito à ação socioeducativa promovida pelo artista, que objetivava dar acessibilidade às artes para comunidades periféricas. A situação material em que os murais se encontram na atualidade revela questões referentes ao patrimônio cultural e ao entendimento que as comunidades escolares têm sobre o seu valor, os conceitos que os envolvem e sua legitimação. Indicam também a falta de consciência dos indivíduos sociais no que diz respeito aos valores culturais que as manifestações populares representam na construção da cultura local e do país, cuja participação torna-se fundamental na legitimação do bem cultural que revela sua identidade e suas memórias, de acordo com os estudos atuais referentes ao patrimônio cultural. A pesquisa trabalhou com base teórica, levantamento e análise documental, investigação de campo e entrevistas com pessoas envolvidas no projeto do artista.

\section{Palavras-chave}

Educação patrimonial - Arte - Patrimônio cultural - Pinturas murais.

\section{Heritage education in the formal teaching: citizen consciousness and participation}

\section{Abstract}

The article elapses from a qualitative research about the mural paintings by plastic artist Luiz Carlos da Silva, known as Luiz Si, in 21 municipal schools in Joinville, performed

1- Universidade da Região de Joinville, Joinville, SC, Brasil. Contatos: larizza.b.a@gmail.com; nadja.carvalho@univille.com. 
during the educational process designed in the project The Artist in Education, idealized and carried out by the artist himself, between 1996 and 2009. The large-size paintings stand out in their representative value as they add, to the landscapes, personalities belonging to the local culture. Its representative value also concerns the socio-educational action promoted by the artist, who aimed to give accessibility to the arts for grass-roots communities. The material situation in which the murals are found nowadays reveals issues related to the cultural heritage and to the understanding that the school communities have about their value, the concepts that surround them in their legitimation. They also indicate the lack of awareness of social individuals regarding cultural values which the popular manifestations represent in the construction of local culture and of the countryside, in which the participation becomes fundamental in legitimating the cultural asset that reveals its identity in its memories, according to the current studies on cultural heritage. The research had a theoretical basis, documents were reviewed and analyzed, fieldwork and interviews were conducted with people involved in the artist's project.

\section{Keywords}

Heritage education - Art - Cultural heritage - Mural paintings.

\section{Introdução}

Diversas são as pesquisas que, na atualidade, discutem a relevância da participação cidadã na legitimação do bem cultural como patrimônio, na tentativa de construir uma narrativa cultural a partir das memórias identitárias de grupos sociais que compõem a pluralidade cultural do país, a exemplo de Zanirato (2006), Meneses (2012), Candau (2011), Nora (1993), Fonseca (2003), entre outros. No entanto, o entendimento do patrimônio cultural ligado às memórias identitárias dos grupos sociais não tem consistência na prática. As pessoas parecem não ter condições de efetivar sua participação por estarem desprovidas de um entendimento sobre a noção de patrimônio cultural, considerando a relevância da pluralidade na construção da representação cultural do país. 0 presente artigo é resultado de uma pesquisa científica intitulada As pinturas murais de Luiz Si nas escolas municipais de Joinville: tensões entre patrimônio, arte e políticas educacionais, que problematiza tais questões e teve como objeto de investigação o trabalho socioeducativo do artista plástico Luiz Carlos da Silva (1941-2011) em 21 escolas municipais de Joinville.

0 projeto socioeducativo O Artista na Educação foi pensado e executado pelo próprio artista no período de 1996 e 2009. Objetivava aproximar a arte da periferia e a periferia da arte em duas ações: a primeira com pinturas murais nas paredes das escolas e, a segunda, com oficinas de pintura e desenho que foram oferecidas gratuitamente no contraturno para alunos interessados. Como parte metodológica do projeto, o artista visitava as turmas com o intuito de apresentar-se enquanto artista, apresentar seu projeto na escola e sua proposta artística para a pintura do mural em uma conversa informal e participativa. 0 tema expresso na pintura mural e o local onde a pintura seria feita foram cuidadosamente pensados com a equipe diretiva da escola em um diálogo participativo na tentativa do artista de articular sua proposta com o contexto local. 
Embora o artista Luiz Si tenha oferecido uma relevante contribuição para o campo da arte em Joinville, tanto como professor de desenho e pintura da Escola de Artes Fritz Alt, contribuindo na formação de novos artistas e interessados em arte, como em seu projeto socioeducativo junto a escolas públicas de Joinville, não havia produção literária sobre o artista e suas obras. Contudo, para que se efetivasse a pesquisa com coerência, fez-se necessário uma pesquisa documental em fontes primárias coletadas no Arquivo Histórico de Joinville e na biblioteca do Museu de Arte de Joinville, para melhor contextualizar o projeto socioeducativo do artista. As fontes utilizadas para a coleta de dados foram: jornais, catálogos de exposições, convites para exposições e a ficha de cadastro do artista. Com isto, a pesquisa contribuiu para a construção documental sobre a biografia do artista e sua trajetória artística. Neste artigo, apresenta-se parte desse resultado, de modo que o texto sobre o artista e sobre suas pinturas é uma construção resultado dessa pesquisa.

A pesquisa seguiu uma abordagem metodológica de natureza qualitativa com coleta e análise da dados subjetivos. Para tanto, a investigação se utilizou de pesquisa bibliográfica, pesquisa documental e pesquisa de campo, cuja coleta de dados subsidiou a construção teórica que fundamenta as pinturas murais enquanto patrimônio cultural, a biografia do artista, o projeto socioeducativo $O$ Artista na Educação e os aspectos relevantes em torno das pinturas murais na atualidade. No que se refere à coleta de dados sobre os murais, utilizou-se da ferramenta metodológica de pesquisa de campo, abrangendo a observação dos murais in loco a fim de averiguar os usos que a comunidade faz dos murais na atualidade e o estado de conservação dos mesmos, e entrevistas com três professoras que, na ocasião da produção dos murais, ocupavam o cargo de diretora, uma delas ainda em exercício, e uma quarta professora que exerce atualmente o cargo de diretora. ${ }^{2}$ A pesquisa documental abrangeu documentos de fontes primárias como fotos, catálogo do artista, artigos de jornais e registros documentais pesquisados na Secretaria de Educação de Joinville, nas secretarias das Escolas Municipais e no Arquivo Histórico de Joinville, na busca por registros sobre a ação educativa do artista nas escolas, sobre o projeto sistematizado e outras informações relevantes.

A pesquisa de campo forneceu dados sobre a metodologia utilizada pelo artista durante a execução de seu projeto, bem como sobre a representação expressa nas pinturas e a condição atual dos murais, tanto no que se refere às condições materiais atuais como aos usos que a comunidade faz do espaço que apresenta o mural. Os dados foram coletados nas entrevistas com perguntas semiestruturadas e na observação in loco com anotações e registro fotográfico. As visitas aconteceram nas dezesseis escolas que ainda têm seu mural. As escolas que tiveram os murais apagados foram contatadas por telefone.

As dificuldades encontras durante a pesquisa decorreram da ausência de registros e arquivos documentais nas escolas no período das produções dos murais, isto é, entre 1996 e 2009. Das 21 escolas contatadas, apenas uma diz ter feito um registro documental sobre o projeto do artista, porém, este não foi encontrado nos registros da escola, apenas arquivos de fotos. As demais escolas alegaram não possuir fotos que registrassem a ação do artista. Algumas fotos foram encontradas no arquivo pessoal de professores que se envolveram

\footnotetext{
2- Diante da abrangência de 21 escolas participantes do projeto do artista, mapeadas durante a pesquisa, e do curto espaço de tempo para 0 desenvolvimento da pesquisa, fez-se necessário um recorte de três escolas que permitisse aprofundar algumas questões ligadas à metodologia do projeto do artista e aos aspectos visuais da obra enquanto linguagem artística.
} 
com o projeto do artista na época. Na Secretaria de Educação foram encontradas fotos que registram as oficinas que o artista ofereceu na E.M. João Bernardino da Silveira, bem como o registro do projeto Inclusão pela Arte, do qual o artista fez parte no ano de 2004 e 2008 , e um pequeno catálogo de fotos com dez murais produzidos pelo artista, que serviu de ponto de partida para o mapeamento dos murais. 0 projeto do artista, sistematizado, não foi encontrado. A construção que se faz aqui é resultado da coleta de dados da pesquisa.

A pesquisa partiu de um mapeamento (Figura 1) das escolas participantes do projeto do artista, o qual revelou o enfoque do artista nas comunidades periféricas de Joinville. 0 mapeamento direcionou o encaminhamento da busca de dados.

Figura 1 - Mapeamento das escolas participantes do projeto de Luiz Si

Fonte: dados da pesquisa.

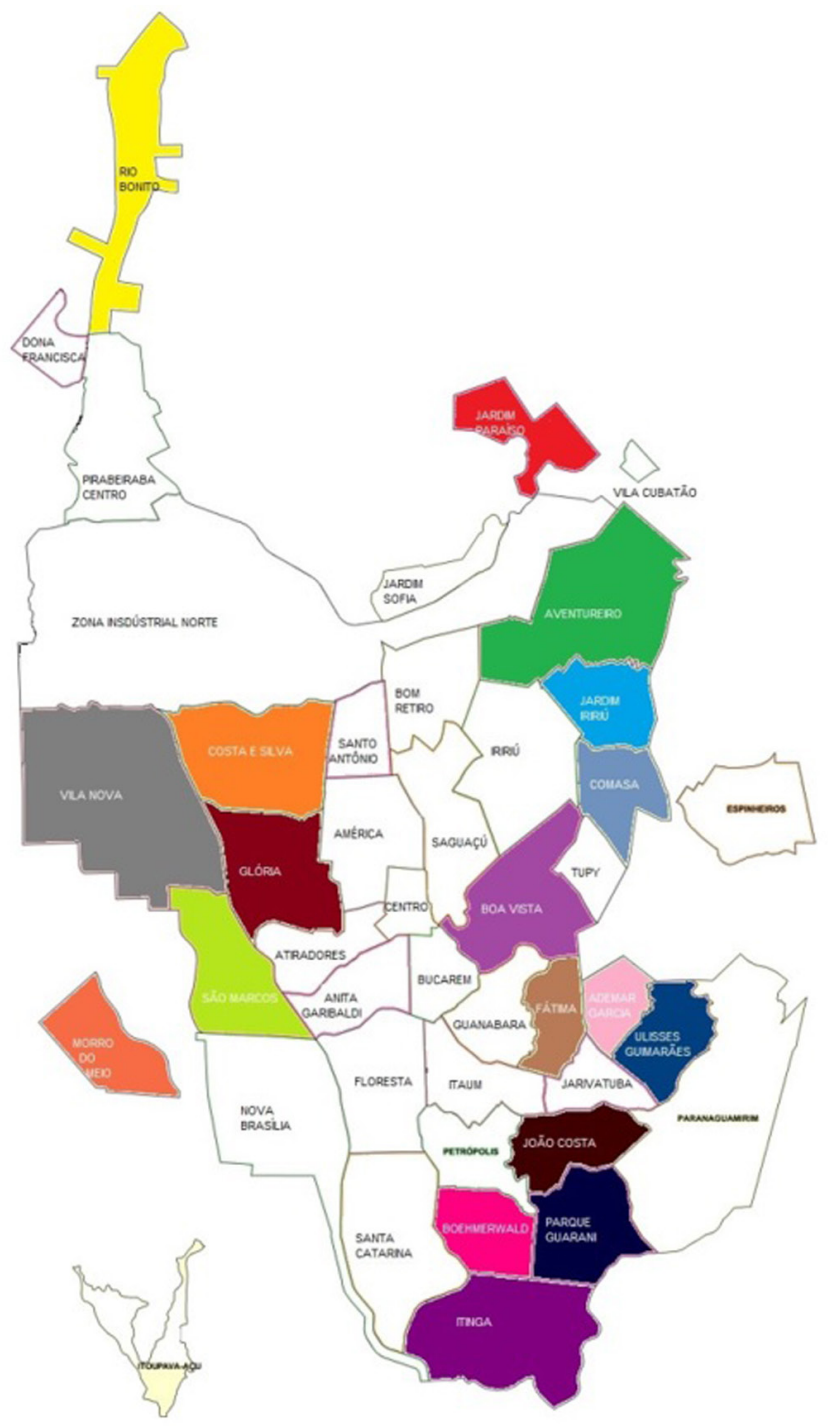




\begin{tabular}{|c|c|}
\hline E. M. Amador Aguiar & E. M.João Bernardino \\
\hline E. M. CAIC Professor Mariano Costa & E. M. João de Oliveira \\
\hline E. M. Doutor José Antônio Navarro Lins & E. M. Paul Harris \\
\hline E. M. Doutor Rubem Roberto Schmidlin & E. M.Pastor Hans Muller \\
\hline E. M. Doutor Sadalla Amin Ghanem & E. M. Presidente Castello Branco \\
\hline E. M. Emílio Paulo Roberto Hardt & E. M. Professor Edgar Monteiro Castanheira \\
\hline E. M. Enfermeira Hilda Anna Krish & E. M. Professor Orestes Guimarães \\
\hline E. M.Governador Heriberto Hülse & E. M.Professora Eladir Skibinski \\
\hline E. M. Governador Pedro Ivo Campos & E. M. Professora Karin Barkemeyer \\
\hline E. M. Hernam Müller & E. M.Professora Lacy Luiza da Cruz Flores \\
\hline & E. M. Professora Rosa Maria Berezoski Demanrchi \\
\hline
\end{tabular}

\section{Luiz Carlos da Silva, o Luiz Si}

Luiz Carlos da Silva nasceu entre os anos de 1938 ou 1939, e foi registrado pelo pai no dia 8 de setembro de 1941, em São José (SC). Faleceu em Florianópolis no dia $1^{\circ}$ de janeiro de 2011, vítima de um acidente vascular cerebral. Filho de Natalino João da Silva e Lourete Maria Nobre. Teve três filhos: Paloma, Paola e Pablo.

0 início de sua carreira artística se deu com o aceite de suas pinturas no Salão Arte Jovem, promovido pelo MAC de Campinas (SP), em 1969.

Por indicação do amigo Lindolf Bell (poeta e proprietário da galeria de arte Açú-Açú, em Blumenau), em 1978 Luiz Si fixou residência em Joinville, onde com a colaboração da Marchand Marina Mosimann e da Galeria de Arte Lascaux engajou-se no meio artístico com participação ativa em exposições, projetos, movimentos e organizações como a Associação dos Artistas Plásticos de Joinville (AAPLAJ), em 1982, a Coletiva de Artistas de Joinville (atuante desde 1971) e demais organizações de difusão das artes plásticas em Joinville, junto a jovens artistas da época, a exemplo de Mário Avancini, Luiz Henrique Schwanke, Hamilton Machado, Antônio Mir, Juarez Machado, Edson Machado, Indio Negreiros, Moacir Moreira (Môa), Amandos Sell, Leda Campos, Linda Suzana Poll, entre outros. Em 1979, foi convidado para dar aulas de pintura na Escola de Artes Fritz Alt da Casa da Cultura Fausto Rocha Junior, onde atuou como professor por 27 anos, tendo, dessa forma, contribuído na formação artística de vários artistas locais e de pessoas envolvidas no movimento artístico de Joinville e região.

No período de 1996 a 2009, idealizou e executou o projeto 0 Artista na Educação, apoiado pela Secretaria de Educação de Joinville, que teve a participação de 21 escolas municipais de Joinville. 0 artista dedicou vinte horas semanais de sua carga horária de professor na Escola de Artes Fritz Alt para executar nas escolas seu projeto, que propunha pinturas murais e oficinas de pintura e desenho oferecidas aos alunos no contraturno das aulas. Após sua aposentadoria, em 2006, continuou o trabalho nas escolas municipais de Joinville voluntariamente, até o ano de 2009.

Sua última exposição (em 7 de dezembro de 2010), intitulada Harmonia e Êxtase, comemorou os quarenta anos de sua carreira artística. Na ocasião, o artista lutava para se recuperar de um AVC. A exposição, apoiada pela Fundação Cultural de Joinville e pelo 
Museu de Arte de Joinville, exibiu obras exclusivas para o evento que ocorreu na casa do amigo e apoiador Edilson Kammradt, e foi a derradeira de uma trajetória em prol da difusão das artes plásticas que o artista encerrou em 2011, com seu falecimento.

Com enfoque na comunidade joinvilense, objetivando a difusão das artes plásticas, a carreira artística de Luiz $\mathrm{Si}$, desenvolveu-se também na formação de novos artistas, como professor de pintura na Escola de Artes Fritz Alt, e no fomento de apreciadores da arte com o projeto socioeducativo nas escolas municipais de Joinville. Tendo em vista a relevância de sua atuação profissional e social, questiona-se o fato de seu nome ser pouco citado no meio artístico de Joinville e de Santa Catarina e a falta de uma produção literária a seu respeito.

\section{Os murais e a representação artística/cultural local}

Do ponto de vista estético, os murais caracterizam uma nova fase artística do pintor, nas quais paisagens multicores aliadas a símbolos de representação da cultura joinvilense provocam um pensar a respeito da relação homem/natureza, ressalta a emergência da discussão ambiental na escola, a partir da representação de alguns elementos naturais típicos de Joinville e região, a exemplo da flor antúrio e da flor copo de leite. Árvores, flores, borboletas, pássaros, céu iluminado, casinhas ao longe, logo se percebe a construção pictórica de paisagens. Há um tom bucólico que harmoniza as formas e as cores, a natureza e as pessoas. As cores suaves transmitem sensação de tranquilidade, de paz e de beleza em torno de um lugar idealizado, onde pássaros e borboletas voam livremente, em calmaria, como se o tempo houvesse parado. Um lugar distante da realidade, uma natureza trabalhada, como se alguém cuidasse dela todos os dias. Um constructo, quase uma colagem de elementos que o artista selecionou para compor sua paisagem sem a preocupação de imitar a natureza, mas simplesmente representá-la de maneira poética e cultural. Nesse contexto, acaba por revelar uma preocupação em refletir sobre a natureza e seu lugar entre os humanos, ou ainda, o lugar dos humanos entre a natureza. Pretende levantar questões acerca da preservação como uma preocupação social de gerar consciência ambiental na relação homem/natureza e natureza/homem, como elementos indissociáveis no planeta.

Além de elementos da natureza, compostos em paisagens, carregados de intenções de cunho ambiental, o artista acrescentou à pintura símbolos que caracterizam aspectos da cultura local, elementos que fazem referências à cultura em Joinville, sua história e memória, a exemplo da casa enxaimel ${ }^{3}$ e do pé de bailarina ${ }^{4}$ ou, ainda, elementos que configuram a memória da escola onde o mural foi realizado (Figura 2).

\footnotetext{
3- 0 estilo arquitetônico enxaimel é uma técnica de construção que consiste em paredes montadas com hastes de madeira encaixadas entre si em posições horizontais, verticais ou inclinadas, cujos espaços são preenchidos por pedras ou tijolos, o que justifica seu nome, enxaimel, que quer dizer enchimento. Os telhados inclinados compõem o caráter estético da construção, ao mesmo tempo em que ajudam a eliminar a umidade e proteger as madeiras da chuva. 0 estilo tem origem na Alemanha e é muito comum em lugares colonizados por alemães. Em Joinville, devido a imigração alemã, o estilo enxaimel é comum em casas e prédios, alguns tombados pela relevância cultural e histórica que conferem à cidade. 4- A figura do pé de bailarina remete à referência cultural ostentada pela cidade de Joinville como cidade da dança, por abrigar a primeira escola do Ballet Bolshoi fora da Rússia e por sediar o maior Festival de Dança amador do mundo, que teve sua 36ª edição em 2018.
} 
Figura 2 - Luiz Carlos da Silva. Sem título. 2001. Acrílica sobre parede. 4,5x3m. E. M. Heriberto Hülse

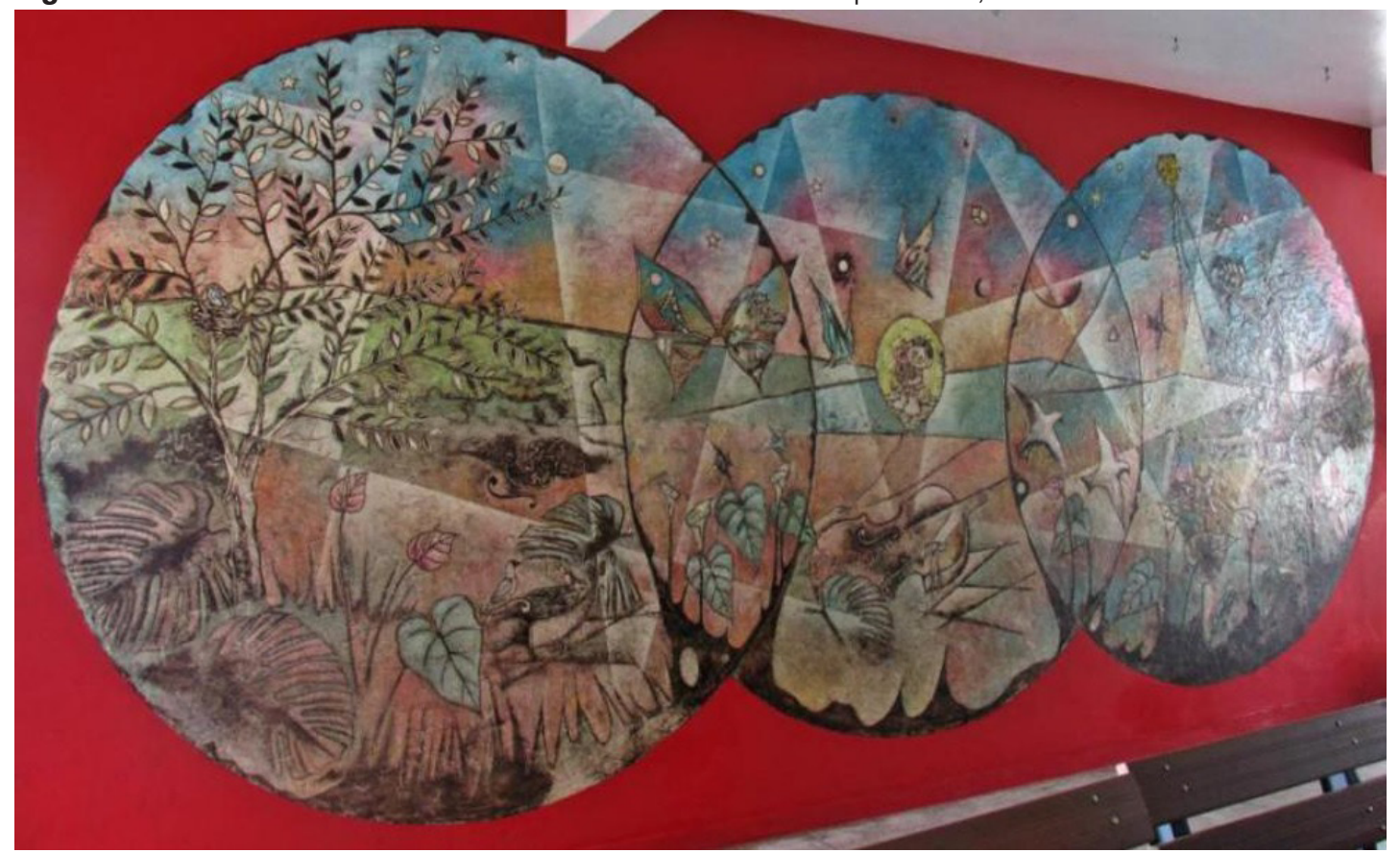

Fonte: Larizza Bergui de Andrade, 2017.

\section{Os murais de Luiz Si hoje}

A pintura mural difere das artes tradicionais por se integrar a uma arquitetura. No campo do patrimônio cultural, é considerada um bem integrado à arquitetura, o qual pode se efetuar de duas formas: desde o planejamento da obra arquitetônica, como parte do projeto arquitetônico na concepção artística ou decorativa, ou, posteriormente, como interferência em uma arquitetura existente e praticada por vários anos. Segundo o documento do Conselho Internacional de Monumentos e Sítios (ICOMOS, 2003), a pintura mural é uma parte integral de monumentos e sítios na categoria de bens integrados. Caracteriza-se por uma intervenção ao cotidiano que afeta os usos, costumes e modos de vida da sociedade em determinada época e cultura, mantendo uma relação com o ambiente. A palavra mural vem de muro ou parede, logo, é uma pintura que tem por suporte a parede ou o muro de um espaço arquitetônico. Os artistas desenvolvem uma proposta a partir de uma interferência imediata, que provoque ou altere, propositalmente, os usos e costumes dos determinados espaços hospedeiros de tais obras, com o compromisso de tornar a arte acessível a todos os públicos, prática usual em culturas de diferentes civilizações que se estende na atualidade e se mostra em diferentes configurações técnicas que seguem o percurso determinado pelo tempo. 
0 manual de preservação da Unesco (2008) destaca dois fatores preocupantes ao processo de preservação da obra de arte: as condições ambientais e a ação humana sobre a obra. Essas premissas de preservação não se aplicam à linguagem dos murais, já que elas são suscetíveis aos dois fatores desde sua execução. Entretanto, numa visão mais conservacionista, ações humanas conscientes podem retardar o processo natural a que os murais estão suscetíveis.

Hoje, os murais de Luiz Si nas escolas municipais de Joinville, incorporados à arquitetura existente, naturalizaram-se no cotidiano escolar e seguem o percurso natural imposto pelo tempo em seu desgaste natural. No entanto, a pesquisa demonstrou que as condições materiais em que as pinturas murais de Luiz Si se encontram na atualidade revelam não somente a ação do tempo, de forma natural, mas a ação agressiva da mão humana a acelerar o processo de deterioração.

Das 21 escolas participantes do projeto de Luiz $\mathrm{Si}$, seis apagaram seus murais durante processo de reforma. Entre as quinze escolas que ainda têm seus murais, o estado atual varia. Dez murais estão em processo acelerado de deterioração e apenas cinco, em bom estado de conservação.

No que diz respeito às ações naturais do tempo, as condições climáticas de Joinville, tanto com relação à oscilação de temperatura quanto ao alto índice de umidade, contribuem significativamente para a deterioração da pintura. Todas as pinturas em que o artista utilizou massa corrida para adquirir textura estão prejudicadas. A massa corrida está se desprendendo da parede, deixando buracos e rachaduras nas pinturas.

A localização das pinturas também pode facilitar o aceleramento do desgaste da pintura. No caso das obras de Luiz Si, a localização segue um padrão de visibilidade; duas estão na escada e rampa de acesso ao piso superior; catorze no hall de entrada; duas na parede externa que dá para a entrada da; duas no auditório e uma no pátio interno.

As que estão localizadas no hall de entrada da escola e na parede externa recebem mais luminosidade, o que contribui para a perda ou diminuição de sua pigmentação. As últimas pinturas, a da Escola Municipal Paulo Roberto Hardt (2007) e da Escola Municipal João Bernardino da Silveira (2008), também se encontram em bom estado de conservação. Entretanto, há indícios visíveis do desgaste da cor na parte em que a luminosidade dos raios solares é mais incisiva. Esse processo altera a tonalidade da cor e compromete a visibilidade da pintura. 0 caso mais agressivo é a pintura da Escola Municipal Hermann Müller, localizada na parede externa, suscetivel às intempéries do clima (Figura 3). Nesses casos, os murais seguem o fluxo natural que o tempo os impõe, concluindo o propósito de seu autor, ou seja, de interferir de forma imediata em uma relação cotidiana, com o objetivo de aproximar a arte do maior número de pessoas possível e diminuir a distância entre arte e periferia, segundo a fala do próprio artista Luiz Si.

Durante a pesquisa de campo, em observação in loco, constatou-se que o segundo fator, e o mais intrigante, responsável pela deterioração da pintura refere-se às ações humanas incididas diretamente sobre a pintura, destacado no documento da Unesco (2008) como fator preocupante.

Dos quinze murais sobreviventes, cinco receberam intervenções diretas nas obras: a pintura da E.M Rubem Roberto Schmidlin com a abertura de uma janela que afetou a parte esquerda da pintura (Figura 4); a da E. M. Edgar Monteiro Castanheira, afetada pela 
colocação de um suporte para ar-condicionado na parte superior esquerda (Figura 5); a pintura da E. M. João Bernardino da Silveira afetada pela colocação de suporte da grade de proteção da porta da secretaria (Figura 6); e o mural da E. M. Prof. Orestes Guimarães sofreu tentativa de apagamento total permanecendo apenas a parte superior da pintura (Figura 7).

Figura 3 - Luiz Carlos da Silva. Sem título. Acrílica sobre parede. E. M. Hermann Müller

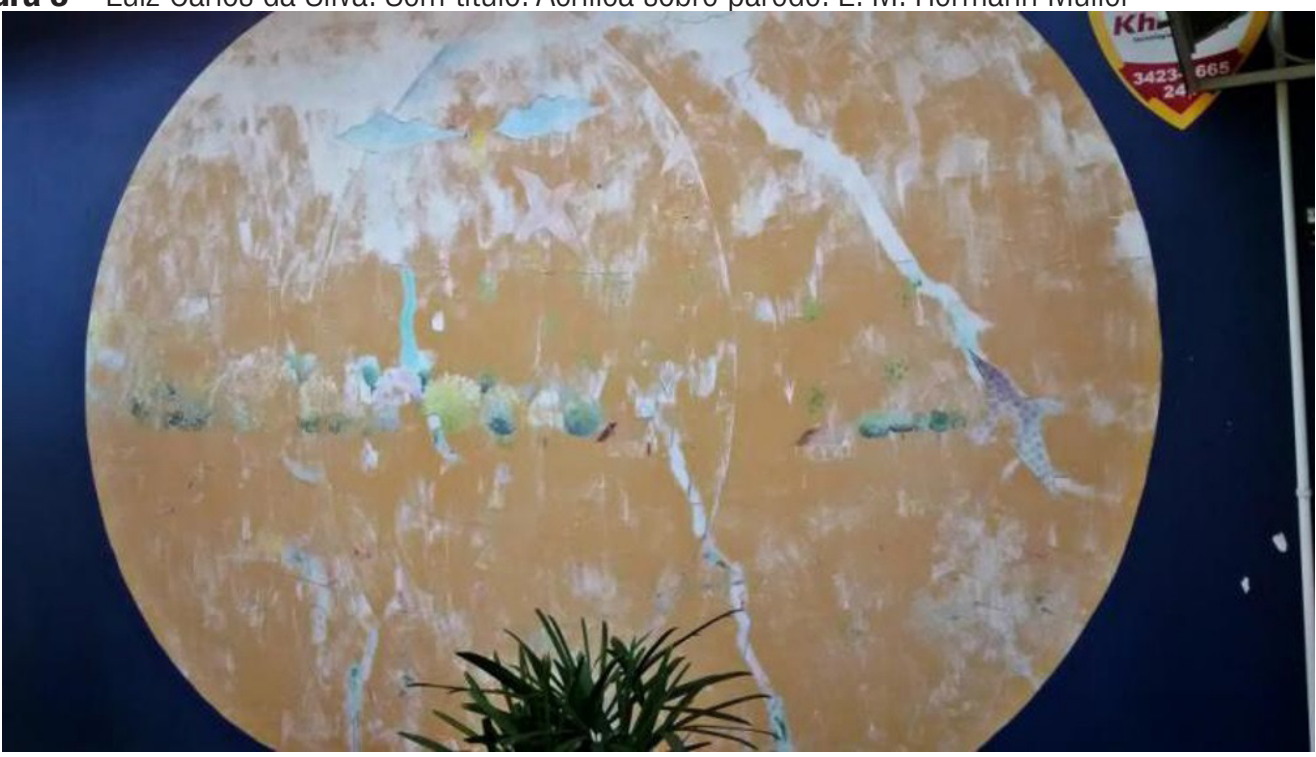

Fonte: arquivo da escola.

Figura 4- Detalhe do mural da E. M. Rubem Roberto Schmidlin

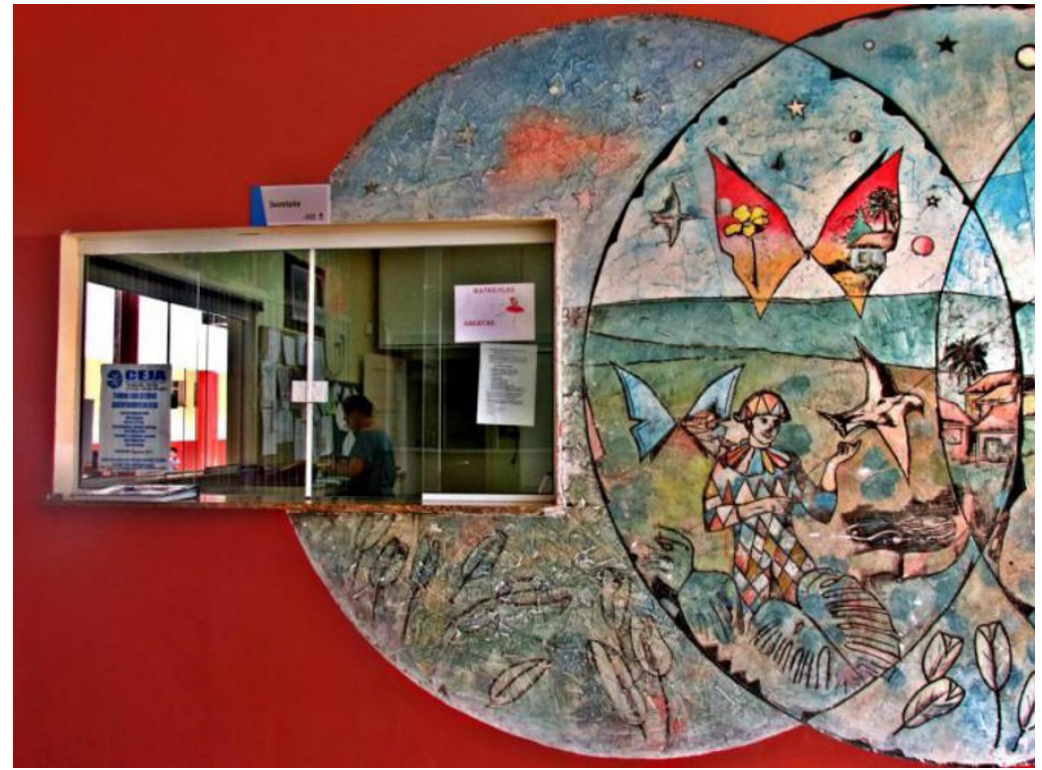

Fonte: Larizza Bergui de Andrade, 2017. 
Figura 5- Detalhe do mural da E. M. Edgar Monteiro Castanheira

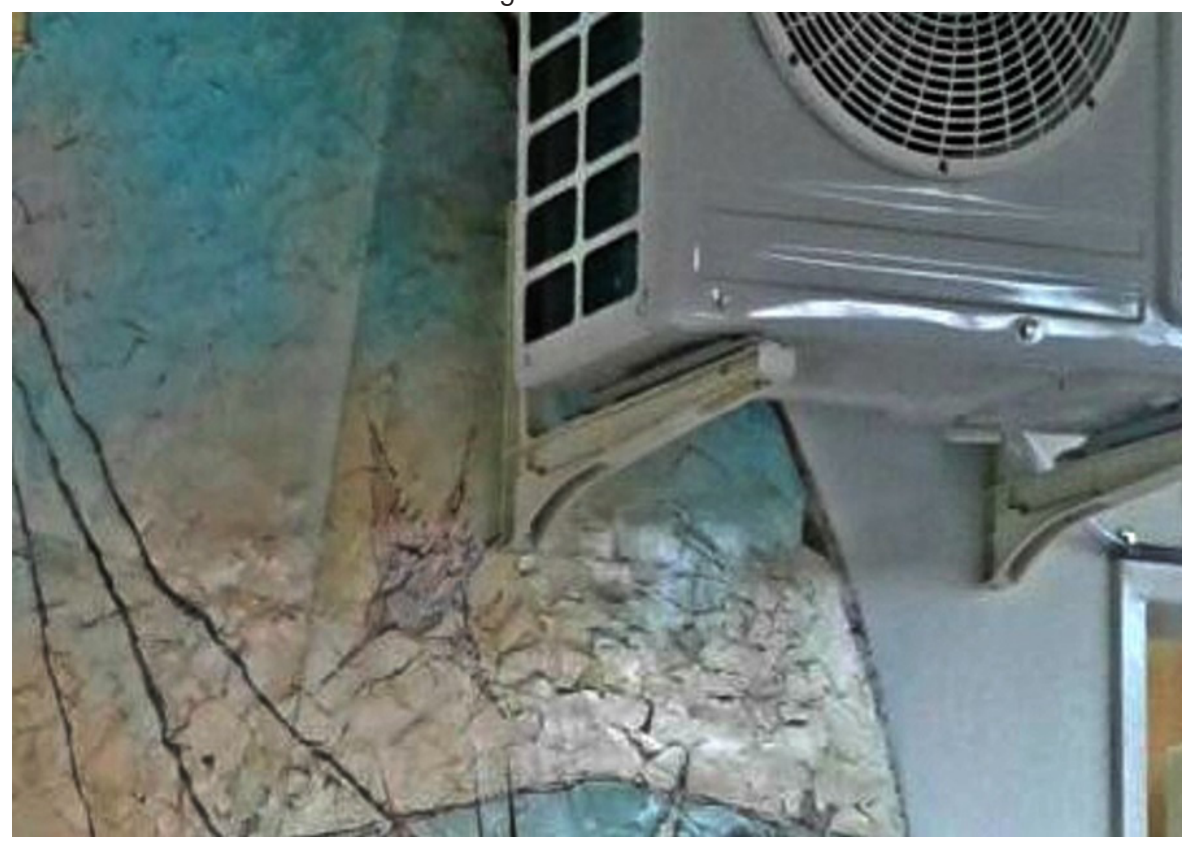

Fonte: Larizza Bergui de Andrade, 2017.

Figura 6 - Detalhe do mural da E. M. João Bernardino da Silveira

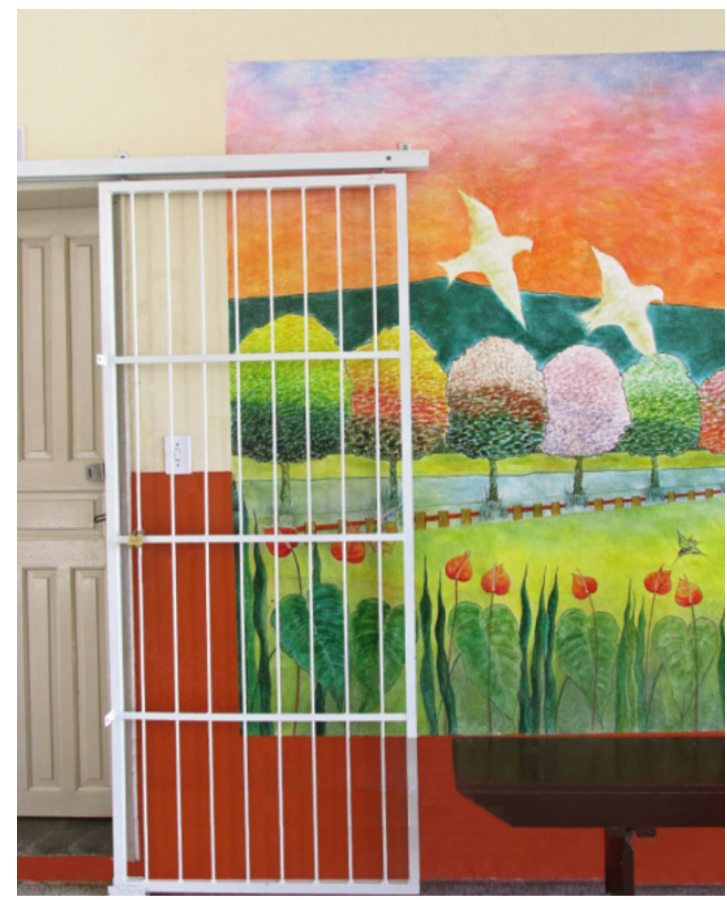

Fonte: Viviane Laurence Borges, 2017. 
Figura 7 - Mural da E. M. Prof. Orestes Guimarães modificado em 2017

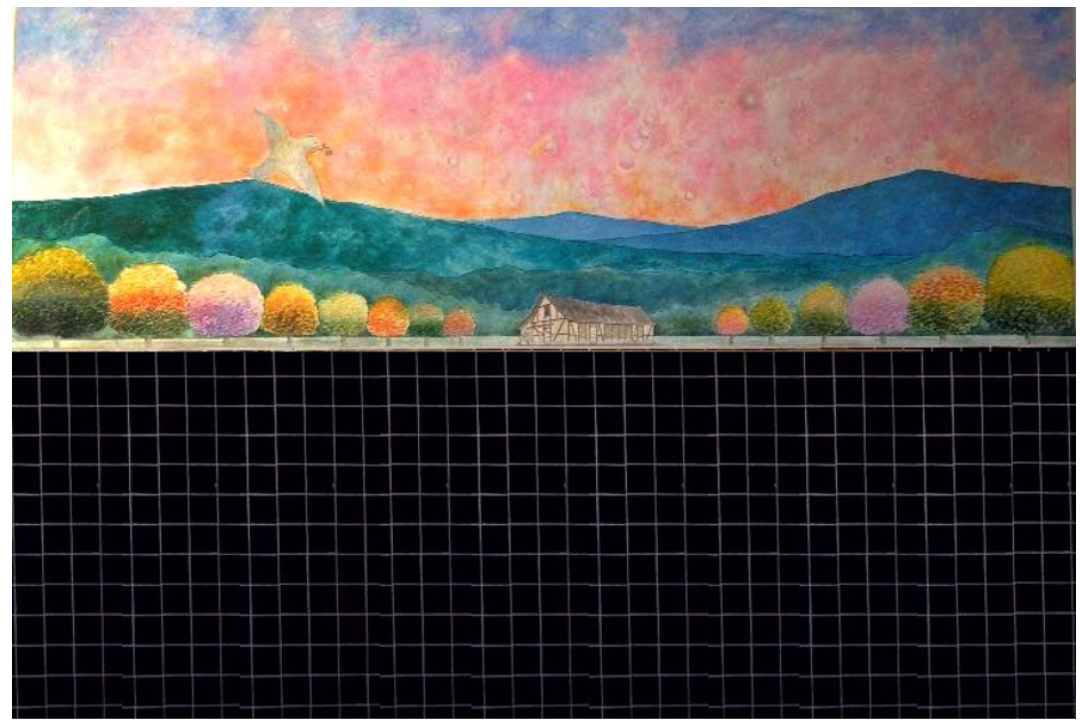

Fonte: Larizza Bergui de Andrade, 2017.

Além dos fatores concernentes à preservação da pintura, apontados pelo documento da Unesco, outro fator refere-se aos usos que a comunidade escolar faz dos locais onde as pinturas estão inseridas. Três escolas mantêm bancos em frente ao mural, o que, além de prejudicar a visibilidade completa da pintura, promove o contato que pode danificá-la (Figura 8). Observam-se fitas adesivas sobre as pinturas, marcas de objetos encostados nela e contato direto de pessoas.

Figura 8- Luiz Carlos da Silva. Sem título. 2006. Acrílica sobre parede. 3×3m. E. M. Pr. Hans Müller

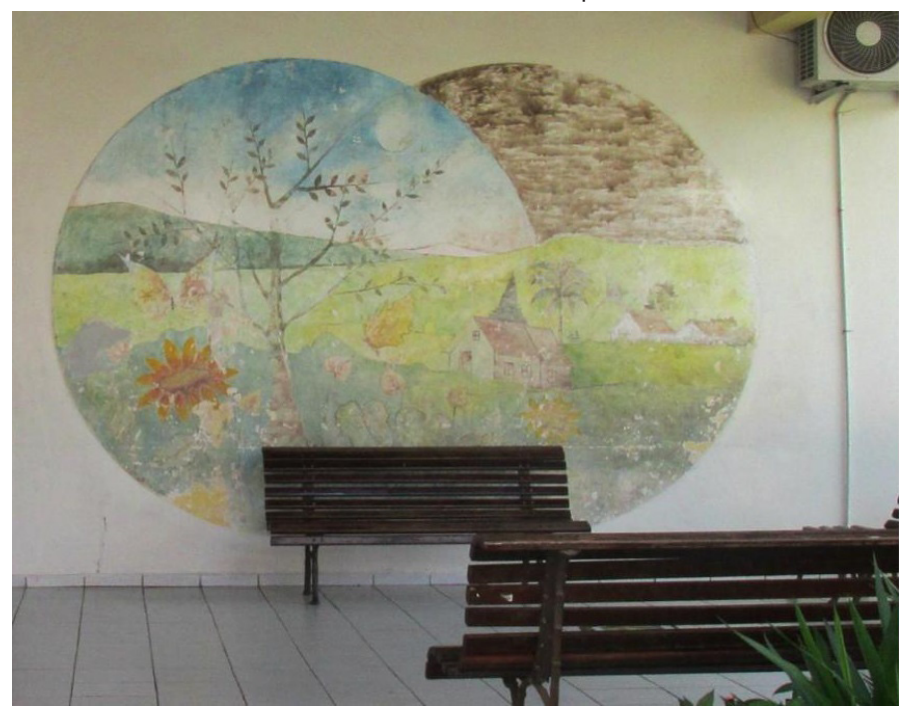

Fonte: Larizza Bergui de Andrade, 2017. 


\section{As pinturas murais e o patrimônio cultural}

Pela observação feita in loco pode-se afırmar que, embora a pintura tenha importância para as pessoas que compõem a coletividade escolar, ela não é vista com um bem cultural que merece ser preservado, e, ainda, não se tem conhecimento das atitudes que prejudicam a obra nem do que poderiam fazer para preservá-la. A comunidade escolar não tem consciência do valor cultural das pinturas de Luiz Si, que são vistas mais no âmbito da decoração, pois a visão que se tem do patrimônio cultural não engloba os aspectos da cultura local. No entanto, os dados coletados na pesquisa mostram o valor cultural das pinturas de Luiz Si pelo viés do patrimônio cultural mesmo que elas não estejam institucionalmente patrimonializadas.

Segundo Zanirato (2006), a visão que a sociedade em geral tem de patrimônio cultural refere-se a um conjunto de monumentos antigos que precisam ser preservados, obras de arte excepcionais ou palcos de eventos marcantes referidos em documentos e em narrativas dos historiadores que não representam a diversidade cultural do Brasil atual. A falta de consciência coletiva sobre o patrimônio cultural desfigura a função patrimonial que está estritamente ligada à pluralidade cultural e à acessibilidade cultural de pequenos grupos, parte da formação cultural do país.

Conforme estudos recentes sobre patrimônio cultural, legitimado institucionalmente por mecanismos e instrumentos de preservação como o tombamento por exemplo, as ações de salvaguarda perdem sua eficácia diante da comunidade quando esta não faz parte do processo de legitimação do bem cultural que a representa. 0 patrimônio cultural deve revelar a cultura produzida no país, nas quais manifestações populares contribuem significativamente para a construção da identidade coletiva, pois, "de um discurso patrimonial referido aos grandes monumentos artísticos do passado, interpretados como fatos destacados de uma civilização, se avançou para uma concepção do patrimônio entendido como o conjunto dos bens culturais, referente às identidades coletivas" (ZANIRAT0, 2006, p. 251).

0 conceito de patrimônio cultural, na atualidade, parte do princípio de que o bem cultural tem uma relevância que ultrapassa a si mesmo, por trazer memórias e lembranças que constroem a identidade coletiva cujo reconhecimento se dá a partir do presente com vistas a projeções futuras. Uma relação de pertencimento gerado em torno da identidade e da memória: "[...] Mecanismos no processo de identidade que nos situa no espaço, assim como a memória nos situa no tempo: são as duas coordenadas que balizam nossa existência” (MENESES, 2012, p. 27). A procura de todo ser humano por seu lugar no tempo e no espaço só é possível pela descoberta da própria identidade enquanto ser social e coletivo que passa pela memória. A memória é a responsável pela construção da identidade do indivíduo: "Sem memória o sujeito se esvazia, vive unicamente o momento presente, perde suas capacidades conceituais e cognitivas. Sua identidade desaparece.” (CANDAU, 2011, p. 60). Neste contexto, percebe-se a memória como fator indispensável na construção da identidade coletiva. Uma identidade não no sentido de uma única identidade nacional, mas de pequenos grupos que se identificam com um franco sentimento de pertencimento a um determinado grupo ou lugar, revelando a diversidade cultural de um país. Segundo Coelho (2008), não são permanentes, mas temporárias, tendo em vista 
os intensos deslocamentos a que a sociedade pós-moderna se submete, impulsionada pela globalização e desterritorialização. No entanto, fatos do passado não podem ser reconstruídos em sua íntegra, tal como ocorreram; por outro lado, as lembranças são capaz de reconstruir e ressignificar o passado, a partir de valores afetivos que projetam, no presente, as dimensões do passado. Trata-se de uma dialética entre as três dimensões temporais: passado-presente-futuro, "porque, a memória organiza os traços do passado em função dos engajamentos do presente e logo por demandas do futuro" (CANDAU, 2011, p. 63). 0 que se escolhe lembrar ou esquecer acontece sempre a partir da vivência do presente. Uma reconstrução de experiências vividas no passado que, no presente, recebem novos significados. Sarlo (2007), em seus estudos sobre o nível de veracidade dos testemunhos pertinentes ao passado, percebe que, ao contrário do que se pensava, a memória não reconstitui o passado, relembra-o; numa dimensão temporal subjetiva, dá seu caráter de passado-presente, numa restauração moral da experiência passada: "Não se deve basear na memória uma epistemologia ingênua” (SARL0, 2007. p. 44). A memória é reconstruída a partir do presente; é em função da sociedade atual que o passado se modifica. Portanto, não se trata de um processo individual, solitário, mas diz respeito a toda uma coletividade que reafirma o ser humano enquanto ser social em sua essência. Mesmo as lembranças que pareçam mais íntimas e individuais assumem caráter coletivo devido às influências sociais ontológicas de cada ser humano (HALBWACHS, 1990).

Segundo Halbwachs (1990), a reconstrução da memória, mesmo no sentido da sua subjetividade, é um processo partícipe na construção da geração atual e das novas gerações. Uma sociedade sem memórias perde o senso de direção e o sentido de ser. Nesse aspecto é que os bens culturais encontram a missão em sua salvaguarda. De acordo com os estudos de Bergson (1999), as imagens disponibilizadas em espaços de cultura são responsáveis por acionar lembranças do passado que recebem novas significações da sociedade atual numa projeção ao futuro. Nora (1993) se refere a esses espaços de cultura denominando-os de lugares de memória, nos quais acontecimentos do passado são lembrados e revisitados pela evocação da memória em um movimento constante de reinvenção que os seres sociais são capazes, tendo em vista o desenvolvimento tecnológico. Portanto, a comunidade deve participar ativamente na construção da representação de sua identidade, de maneira que revele, de fato, suas memórias e sua cultura, tendo em vista o movimento transformador da mesma: “[...] a 'representatividade' dos bens, em termos de diversidade social e cultural do país, é essencial para que a função de patrimônio se realize, no sentido que os diferentes grupos sociais possam se reconhecer neste repertório" (FONSECA, 2003, p. 65). Desta forma, faz-se necessário rever os critérios de preservação adotados pelas instituições para procedimentos que se abram à participação da sociedade no processo de construção e apropriação de seu patrimônio cultural, priorizando a relação da sociedade com sua cultura. Para Fonseca,

[...] é necessário que a ação de "proteger" seja precedida pelas ações de "identificar" e "documentar" - bases para a seleção do que deve ser protegido -, seguida pelas ações de "promover" e "difundir", que viabilizam a reapropriação simbólica e, em alguns casos, econômicas e funcional dos bens preservados. (FONSECA, 2003, p. 65). 
De acordo com as bases teóricas apontadas, dois pontos relevantes se destacam, tendo em vista uma concepção de patrimônio cultural na qual deva-se ampliar a visão que diz respeito à participação cidadã na seleção e preservação dos bens culturais, funções antes atribuídas exclusivamente ao tombamento. Nos dois aspectos, o envolvimento da população inserida no contexto social da cidade e instrumentalizada, consciente dos valores culturais da qual se sente pertencente, tem papel fundamental para que se concretize a função social do patrimônio cultural.

0 manual de preservação da Unesco (2008) citado acima destaca dois fatores preocupantes ao processo de preservação que entram em conflito com a linguagem das pinturas murais, tendo em vista sua exposição a esses dois fatores desde sua produção. Entretanto, numa visão mais preventiva, há procedimentos que podem retardar o processo natural a que os murais estão suscetíveis. Brandi (2004) orienta, na teoria da restauração, para uma ação preventiva, na qual a preservação se efetiva pela remoção dos perigos, de modo a garantir condições favoráveis para a durabilidade da obra de arte como um caminho a amenizar a violência do tempo e das ações humanas sobre a obra. Ainda segundo Brandi (2004), a restauração não se define apenas por sua ação prática operada sobre a matéria, mas por providências tomadas para assegurar, no futuro, a conservação da obra de arte como imagem e como matéria.

0 estado atual em que os murais de Luiz Si se encontram revelam o desconhecimento, por parte da comunidade escolar, sobre o trato com a obra de arte, fato que tem acelerado o processo de deterioração.

Os instrumentos institucionalizados de preservação do patrimônio cultural brasileiro têm a intenção de salvaguardar os bens culturais do país com enfoque em sua pluralidade a fim de construir um patrimônio que tenha coerência com a vivência social e cultual de seu povo. As primeiras manifestações em direção à proteção e salvaguarda de bens culturais no Brasil foi a criação do Instituto do Patrimônio Histórico Artístico Nacional (Iphan) pelo Decreto-lei no 25 de 30 de novembro de 1937, após o documento redigido por Mário de Andrade. ${ }^{5}$ Num primeiro momento, o instituto dedicou-se a iniciativas educativas, como: criação de museus, tombamento de coleções artísticas e documentais, exemplares da arquitetura religiosa, civil, militar e na divulgação jornalística, com o intuito de informar os valores culturais do país. Mário de Andrade acreditava que, apenas pela educação popular, os bens culturais poderiam ser preservados.

Hoje, o instituto é uma autarquia federal, vinculada ao Ministério do Turismo, que responde pela preservação do patrimônio cultural brasileiro, tendo como função principal proteger e promover os bens culturais do país, assegurando sua permanência e usufruto para as atuais e futuras gerações. Responde, também, pela conservação, salvaguarda e monitoramento dos bens culturais brasileiros inscritos na lista de patrimônio mundial e na lista de patrimônio cultural imaterial da humanidade. 0 Iphan, em parceria com os governos estaduais, zela pelo cumprimento dos marcos legais, efetivando a gestão do patrimônio cultural brasileiro e dos bens reconhecidos pela Unesco como patrimônios da humanidade.

5- Esta parte do texto referente ao Iphan e aos procedimentos de preservação e salvaguarda de bens culturais por ele adotados foram retiradas do texto publicado no site do IPHAN. Disponível em: <http://portal.iphan.gov.br/pagina/detalhes/218>. Acesso em: 9 dez. 2017. 
A Constituição Brasileira de 1988 ampliou o conceito de patrimônio cultural estabelecido pelo Decreto-lei no 25 de 30 de novembro de 1937. A constituição incorporou o conceito de referência cultural, reconhecendo como patrimônio referências culturais de natureza material e imaterial. ${ }^{6}$ Em seu artigo 216, define o patrimônio cultural brasileiro com seus bens de ordem material e imaterial:

Art. 216. Constituem patrimônio cultural brasileiro os bens de natureza material e imaterial, tombados individualmente ou em conjunto, portadores de referência à identidade, à ação, à memória dos diferentes grupos formadores da sociedade brasileira, nos quais se incluem: I - as formas de expressão; II - modos de criar, fazer e viver; III - as criações científicas, artísticas e tecnológicas; IV - as obras, objetos, documento, edificações e demais espaços destinados às manifestações artístico-cultural; V - os conjuntos urbanos e sítios de valor histórico, paisagístico, artístico, arqueológico, paleontológico, ecológico e científico. (BRASIL, 1988).

0 documento prevê, também, que a proteção, de responsabilidade do poder público com a colaboração da comunidade, se efetivará por meio de inventário, registro, vigilância, tombamento e desapropriação, entre outras formas cautelares de prevenção. Atualmente, o Iphan determina os instrumentos de preservação do patrimônio material e imaterial, que visam garantir legalmente a preservação dos bens culturais do país que foram definidos por várias legislações ao longo do tempo: o tombamento, a valoração do patrimônio cultural ferroviário, a chancela da paisagem cultural. Os bens são escritos em um dos livros do tombo de acordo com sua natureza: livro do tombo arqueológico, etnográfico e paisagístico; livro do tombo histórico; livro do tombo das belas artes; e livro do tombo das artes aplicadas.

0 tombamento foi instituído como o primeiro instrumento de preservação de bens materiais pelo Decreto-lei n ${ }^{\circ} 25$ de 30 de novembro de 1937. ${ }^{7}$ Aplica-se à proteção de edificações, paisagens e conjunto histórico urbano, proíbe a destruição de bens culturais inscrito em, pelo menos, um dos quatro livros do tombo, bens culturais cuja preservação é de interesse público por sua vinculação a fatos da história do Brasil, quer por seu excepcional valor arqueológico ou etnográfico, bibliográfico ou artístico. 0 objetivo de um tombamento é impedir a destruição ou mutilação de bens culturais, mantendo-os para gerações futuras.

No que se refere à pintura mural, as dificuldades e os conflitos em torno da preservação e do restauro se agravam. Os instrumentos institucionalizados de preservação parecem não dar conta do conceito de arte na atualidade, sobretudo, das pinturas murais que contam com as diretrizes das cartas e documentos quando se trata de preservação e restauro.

\footnotetext{
6- 0 patrimônio de natureza material é assim denominado por constituir de uma materialidade, a exemplo de casas, cidades, sítios arqueológicos, obras de arte, entre outros. 0 patrimônio de natureza imaterial refere-se a bens culturais que não apresentam uma materialidade, a exemplo de comidas, festividades, rituais, modos de fazer, entre outros. No entanto, há estudos que questionam essa separação discriminada das duas naturezas do patrimônio visto que são interdependentes, todo bem material possui uma representação imaterial nele embutida e todo bem imaterial depende de uma materialidade em algum contexto.

7- Os instrumentos de preservação descritos nesta parte do texto foram retirados do site do Iphan. Disponível em <http://portal.iphan.gov.br/ pagina/detalhes/275>. Acesso em: 9 dez. 2017.
} 
As cartas e documentos internacionais sobre o patrimônio cultural trazem recomendações e orientações que fundamentam a preservação dos bens culturais. Ainda que tenham autoridade legal ou configurem uma teoria, têm importância significativa para as autoridades, funcionando como diretrizes de gerenciamento. A arte mural vem sendo citada como bem integrado em várias dessas cartas e documentos desde o início do século XX. Em 2003, foram promulgados os princípios do Conselho Internacional de Monumentos e Sítios (ICOMOS) ${ }^{8}$ para a preservação e conservação: restauro das pinturas murais. 0 documento determina dez princípios básicos que norteiam as práticas da preservação, diretamente direcionados às pinturas murais que versam por diretrizes, como: inventário, pesquisa científıca multidisciplinar, registros documentais, conservação preventiva, intervenções mínimas, considerando a pintura como um bem integrado, medidas de emergência, investigação e informação pública, qualificação profissional na área de restauro para intervir no patrimônio, incentivar práticas e técnicas tradicionais e, por último, cooperação internacional e interdisciplinar de profissionais da área, de outros países. Os demais aspectos nacionais, regionais e locais devem ser acrescidos de acordo com as particularidades de cada região. No entanto, as pinturas murais da atualidade carecem de novas perspectivas em torno da preservação e do restauro, tendo em vista a efemeridade embutida em seu conceito.

As pinturas murais do artista plástico Luiz Si nas escolas municipais de Joinville desafiam e problematizam a visão de patrimônio artístico e os instrumentos de preservação e conservação institucionalizados na atualidade. A localização da obra e seu entorno, enquanto bem integrado, tem papel importante tanto na compreensão de seu significado e de seu valor cultural, como em sua preservação material. Incorporados em uma arquitetura existente, estão vulneráveis a alterações que contemplarão necessidades das gerações futuras e as condições materiais e ambientais do espaço ao qual está integrado. Portanto, pela visão da preservação e do restauro, a arte mural, como bem integrado, implica combinar aspectos da preservação arquitetônica e da preservação da obra de arte. 0 sucesso da intervenção pelo restauro depende da articulação dessas duas áreas (WILHELM, 2011).

\section{Patrimônio cultural e políticas educacionais}

Considerando a relevância da participação cidadã na seleção e preservação do bem cultural que configura a memória identitária da coletividade da qual pertença, propõe-se discutir o patrimônio cultural no ensino formal objetivando instrumentalizar o cidadão para que tenha condições de se incluir culturalmente de forma ativa na construção da cultura da cidade, em defesa da cultural local. Segundo Segala (2005, p. 2), "a ideia de preservação do patrimônio cultural se articula, pois, estreitamente ao seu conhecimento e ao seu uso social, à ciência e a consciência de patrimônio”. As discussões sobre o patrimônio cultural não podem estar restritas a uma minoria privilegiada, detentora de poder político,

8- Documento elaborado pelos membros do ICOMOS de diferentes países a partir de reuniões realizadas entre 28 de outubro e 1 de novembro de 2002 em Copenhague, finalizado em 8 e 9 de maio de 2003 em Salonica. Disponível em: <http://www.patrimonio-santarem.pt/imagens/3/ principios_para_a_preservacao_das_pinturas_murais.pdf>.Acesso em: 12 jan. 2018. 
financeiro ou jurídico, pois, se o discurso referente ao patrimônio cultural se sustenta em torno da população e suas manifestações culturais, faz-se necessário que a mesma esteja estritamente envolvida. Pois, segundo Fonseca (2003), o envolvimento da comunidade no processo de legitimação do bem cultural é essencial para que a função de patrimônio se realize. Faz-se necessário que a comunidade, instrumentalizada, tenha condições de determinar o reconhecimento de seus bens culturais no sentido de preservar sua identidade revelada pelas memórias, tendo em vista o movimento constante de transformação que a sociedade sofre a cada nova geração (CANCLINI, 2008). Riegl (2014) acreditava que, pela educação, as pessoas poderiam compreender melhor o valor de um monumento e colaborar nas discussões de sua preservação. A partir daí é que se entende a importância da inserção do tema educação patrimonial no ensino formal, embora não se encontre, ainda, muitos teóricos que fundamentem essa questão no campo da educação. Com esse intuito, o Iphan, desde sua criação em 1937, investe em educação para o patrimônio nos espaços educacionais não formais, a exemplo de museus, institutos, parques ecológicos e outros espaços culturais nos quais metodologias pedagógicas são aplicadas a fim de educar a população acerca das referências nacionais da história e da cultura do país. Em 2014, o Iphan lançou a segunda edição da revista Educação Patrimonial: histórico, conceitos e processos, cujo enfoque direciona-se para discussões sobre as ações educacionais voltadas para a inserção do tema patrimônio cultural na educação formal. Essa inserção é proposta a partir do Programa Mais Educação ${ }^{9}$ com atividades de Educação Patrimonial, dentro de uma perspectiva da educação integral por meio do acesso e contato com espaços culturais locais que carregam o conceito de espaços educativos. A principal atividade do Programa Mais Educação é um inventário pedagógico do patrimônio local. Trata-se de fichas que deverão coletar dados e classificar os diversos bens culturais como lugares, objetos, celebrações, formas de expressão ou saberes. Inicia-se um tímido processo a respeito da educação patrimonial dentro do ensino formal. Embora tenha sido um passo importante, ainda é uma proposta tímida, visto que nem todas as crianças são atingidas pelo programa (cada escola seleciona um pequeno grupo para participação). Estudos recentes acerca do patrimônio cultural justificam a relevância da inserção do tema na educação formal, tendo em vista a importância da participação cidadã no processo de legitimação do bem cultural (FONSECA, 2003). A revista Educação Patrimonial: histórico, conceitos e processos propõe, ainda, uma abordagem transversal do tema patrimônio cultural de forma interdisciplinar ou transdisciplinar, potencializando o uso dos espaços públicos como espaços formativos. Explorar, nas escolas, os espaços locais de cultura com o intuito de compreender melhor o que são esses espaços e suas finalidades e, a partir daí, acessar processos culturais mais abrangentes, compreendendo a diversidade cultural em seu entorno, não no sentido de fechar-se no localismo, mas

[...] partir de referências culturais locais para, por meio delas, acessar processos sociais e culturais mais amplos e abrangentes, em um registro no qual cada sujeito, com base em seu repertório

9 - 0 Programa Mais Educação é uma estratégia do governo federal de introduzir a ampliação da jornada escolar e a organização do currículo, na perspectiva da educação integral. 
de referência, possa compreender e refletir tanto sobre contextos inclusivos quanto sobre a diversidade cultural que o cerca. (FLORÊNCIO, 2014, p. 27).

A educação formal pode contribuir para a apropriação do conhecimento quanto à cultura local, desde que entendida a partir de uma perspectiva de educadores/mediadores para a apropriação do conhecimento numa construção coletiva, e não como meros receptores e consumidores de informação (FLORÊNCIO, 2014).

Entendendo a relevância do tema a ser abordado na educação formal, a Base Nacional Comum Curricular (BRASIL, 2017) propõe, em todas as áreas do conhecimento, uma abordagem educacional referente ao patrimonial cultural material e imaterial local e de outras culturas, sobretudo as que contribuíram na construção da cultura brasileira, como a indígena, a africana e a europeia de matizes e épocas diferentes.

$\mathrm{Na}$ área de linguagens, composta pelos componentes curriculares de língua portuguesa, arte, educação física e língua inglesa, a BNCC propõe o reconhecimento das linguagens como patrimônio cultural: "Reconhecer as linguagens como parte do patrimônio cultural material e imaterial de uma determinada coletividade e da humanidade" (BRASIL, 2017, p. 62).

No componente curricular arte, o tema patrimônio histórico e cultural da humanidade é citado como objeto do conhecimento na unidade temática artes integradas, em que se espera "reconhecer e valorizar o patrimônio cultural, material e imaterial, de culturas diversas, em especial a brasileira, incluindo-se suas matizes indígenas, africanas e europeias de diferentes épocas, favorecendo a construção de vocabulário e repertório, relativos à diferentes linguagens artísticas" (BRASIL, 2017, p.160).

$\mathrm{Na}$ área de ciências da natureza, o patrimônio é citado nas formas de preservação da biodiversidade, prevendo a habilidade de "justificar a importância das unidades de conservação para a preservação da biodiversidade e do patrimônio nacional, considerando os diferentes tipos de unidades (parques, reservas e florestas nacionais), as populações humanas e atividades a eles relacionados" (BRASIL, 2017, p. 303).

$\mathrm{Na}$ área de ciências humanas, composta pelos componentes curriculares geografia e história, o tema patrimônio cultural é abordado como referência de proteção da cultura e da história brasileira, considerando a produção das memórias que identificam os grupos sociais e suas relações de pertencimento: "No interior de uma sociedade, há formas de registros variados, e que cada grupo produz suas próprias memórias como elemento que impulsiona o estabelecimento de identidades e o reconhecimento de pertencimento a um grupo social determinado" (BRASIL, 2017, p. 355).

Considerando o patrimônio cultural como um bem que representa as memórias e a identidade de pequenos grupos sociais, que, por sua vez, constituem a cultura do país reconhecendo-a em sua pluralidade, a referência da BNCC ao patrimônio enquanto conteúdo programático é muito abrangente. Sugere-se discutir o patrimônio cultural a partir das próprias construções de memórias, nas quais a valorização das manifestações e das expressões locais permitem refletir, também, sobre outras referências culturais do país e de outras civilizações. 0 fortalecimento das relações das pessoas com sua herança cultural imputa responsabilidades de valorização e preservação do patrimônio cultural, o que, por sua vez, promove a cidadania enquanto indivíduo partícipe do processo, incluído na sociedade. 
A inserção da abordagem ao patrimônio cultural no ensino formal como ferramenta de articulação de conhecimentos pertinentes às demandas sociais vigentes somará esforços que contribuirão para a formação consciente sobre o patrimônio cultural como gerador da participação na construção da cultura social, de forma democrática e inclusiva.

\section{Considerações finais}

A pesquisa apresentada tensiona aspectos significativos em torno do patrimônio cultural e da educação patrimonial. Dentre eles, destacam-se dois fatores importantes, sobre os quais os resultados da pesquisa provocaram discussões. 0 primeiro se refere à preservação de pinturas murais e suas complexidades, levando em conta sua materialidade, o segundo diz respeito à participação cidadã no processo de legitimação do bem que reflete a cultura local de grupos sociais. Nos dois aspectos, a população local, instrumentalizada pela educação patrimonial, consciente dos valores culturais da comunidade da qual se sente pertencente, tem papel fundamental na concretização da função social do patrimônio cultural. As pinturas murais de Luiz Si em 21 escolas municipais de Joinville podem ser o ponto de partida para tais discussões. Concebidas como espaço cultural e patrimônio local, elas podem estabelecer ligações culturais que ultrapassam o localismo e a arte, enquanto área de conhecimento.

Do ponto de vista de seu valor cultural, as pinturas interagem com as lembranças culturais da comunidade local e reafirmam uma identidade construída e sustentada pela própria comunidade. 0 trabalho do artista nas escolas estabelece uma relação com espaços de uso cotidiano ao se inserir à arquitetura existente e praticada por décadas. Assim, revela em si um valor simbólico que ultrapassa os valores de sua materialidade e o integra aos bens culturais como parte da construção identitária daquela determinada coletividade, constituindo-se como parte da coleção patrimonial da comunidade e da cidade de Joinville como um todo. É preciso fomentar a consciência cultural para que cidadãos, instrumentalizados, possam contribuir para a construção do patrimônio cultural da cidade e do país pelo acesso democrático à cultura.

\section{Referências}

BERGSON, Henri. Matéria e memória. São Paulo: Martins Fontes, 1999.

BRANDI, Cesare. Teoria da restauração. São Paulo: Ateliê, 2004.

BRASIL. Constituição da República Federativa do Brasil; promulgada em 5 de outubro de 1988. Disponível em: <http://www.amperj.org.br/store/legislacao/constituicao/crfb.pdf>. Acesso em: 9 dez. 2017.

BRASIL. Ministério da Educação. Base Nacional Comum Curricular. Brasília, DF: MEC, 2017.

CANCLINI, Nestor Garcia. Culturas híbridas: estratégias para entrar e sair da modernidade. Tradução Ana Regina Lessa e Heloisa Pezza Cintrão. 4. ed. São Paulo: Edusp, 2008.

CANDAU, Joel. Memória e identidade. São Paulo: Contexto, 2011. 
CAUQUELIN, Anne. A invenção da paisagem. São Paulo: Martins, 2007.

COELHO, Teixeira. A cultura e seu contrário: cultura, arte e política pós-2001. São Paulo: lluminuras: Itaú Cultural, 2008.

FLORÊNCIO, Sônia Rampim et al. Educação patrimonial: histórico, conceitos e processos. Brasília, DF: Iphan, 2014.

FONSECA, Maria Cecília Londres. Para além da pedra e cal: por uma concepção ampla de patrimônio cultural. In: FONSECA, Maria Cecília Londres. Memória e patrimônio: ensaios contemporâneos. Rio de Janeiro: DP\&A, 2003. p. 56-76.

HALBWACHS, Maurice. A memória coletiva. São Paulo: Vértice, 1990.

ICOMOS. Princípios do Icomos para a preservação e conservação: restauro de pinturas murais, 2003. Disponível em: <http://www.patrimonio-santarem.pt/imagens/3/principios_para_a_preservacao_das_ pinturas_murais.pdf>. Acesso em: 12 jan. 2018.

IPHAN 80 anos (1937-2017). Patrimônio Cultural. Disponível em: <http://portal.iphan.gov.br/pagina/ detalhes/218 >. Acesso em: 9 dez. 2017.

MENESES, Ulpiano Bezerra de. 0 campo do patrimônio cultural: uma revisão de premissas. In: MENESES, Ulpiano Bezerra de. FÓRUM NACIONAL DE PATRIMÔNIO CULTURAL: sistema nacional de patrimônio cultural: desafios, estratégias e experiência para uma nova gestão, 1., 2009, Ouro Preto. I Fórum... v. 1. Brasília, DF. Iphan, 2012. p. 25-39.

NORA, Pierre. Entre memória e história: a problemática dos lugares. Tradução de Yara AunKhoury. São Paulo: [s. n.], 1993. p. 7-28. (Projeto história; n. 10).

RIEGL, Alóis. 0 culto moderno dos monumentos: a sua essência e sua origem. São Paulo: Perspectiva, 2014.

SARLO, Beatriz. Crítica do testemunho: sujeito e experiência. In: SARLO, Beatriz. Tempo passado: cultura da memória e guinada subjetiva. Belo Horizonte: UFMG; São Paulo: Cia das Letras, 2007. p. 23-44.

SEGALA, Lygia. Identidade, educação e patrimônio: o trabalho da Lapoep. Iphan, Brasília, DF, n. 32, 2005.

UNESCO. Caderno de conservação e restauro de obras de arte popular brasileira / Museu Casa do Pontal. Rio de Janeiro: Associação dos Amigos da Arte Popular Brasileira; Brasília, DF: Unesco, 2008.

WILHELM, Vera Regina Barbuy. Arte mural e a prática da preservação. 2011. 254f. Tese (Doutorado em História e Fundamentos da Arquitetura e do Urbanismo) - Faculdade de Arquitetura e do Urbanismo da Universidade de São Paulo, São Paulo, 2011.

ZANIRAT0, Silvia Helena et al. Patrimônio cultural: a percepção da natureza como um bem não renovável. Revista Brasileira de História, São Paulo, v. 26, n. 51, p. 251-262, 2006. 
Recebido em: 30.01.2019

Revisado em: 08.05.2019

Aprovado em: 04.06.2019

Larizza Bergui de Andrade possui mestrado em patrimônio cultural e sociedade pela Universidade da Região de Joinville (Univille) na linha de pesquisa Patrimônio e Memória Social (2018). Graduada em educação artística (2000) pela Univille. Integrante do Grupo de Estudos em Arte, Cultura e Patrimônio (Gearcupa). Atualmente é doutoranda em patrimônio cultural e sociedade pela Univille.

Nadja de Carvalho Lamas possui doutorado em artes visuais pela Universidade Federal do Rio Grande do Sul (UFRGS), doutorado sanduíche pela Université Paris 1 - Panthéon Sorbonne, mestrado em Artes Visuais pela UFRGS, especialização em arte na educação pela Faculdade de Artes do Paraná (FAP) e graduação em administração pela Fundação Educacional da Região de Joinville (FURJ). É professora titular da Universidade da Região de Joinville (Univille) nos cursos de Artes Visuais, Publicidade e Propaganda e no mestrado e doutorado em patrimônio cultural e sociedade. 